\title{
Adsorption of copper (II) on mesoporous silica: the effect of nano-scale confinement
}

CrossMark

Andrew W. Knight, Austen B. Tigges and Anastasia G. Ilgen*

\begin{abstract}
Nano-scale spatial confinement can alter chemistry at mineral-water interfaces. These nano-scale confinement effects can lead to anomalous fate and transport behavior of aqueous metal species. When a fluid resides in a nanoporous environments (pore size under $100 \mathrm{~nm}$ ), the observed density, surface tension, and dielectric constant diverge from those measured in the bulk. To evaluate the impact of nano-scale confinement on the adsorption of copper $\left(\mathrm{Cu}^{2+}\right)$, we performed batch adsorption studies using mesoporous silica. Mesoporous silica with the narrow distribution of pore diameters (SBA-15; 8, 6, and $4 \mathrm{~nm}$ pore diameters) was chosen since the silanol functional groups are typical to surface environments. Batch adsorption isotherms were fit with adsorption models (Langmuir, Freundlich, and Dubinin-Radushkevich) and adsorption kinetic data were fit to a pseudo-first-order reaction model. We found that with decreasing pore size, the maximum surface area-normalized uptake of $\mathrm{Cu}^{2+}$ increased. The pseudo-firstorder kinetic model demonstrates that the adsorption is faster as the pore size decreases from 8 to $4 \mathrm{~nm}$. We attribute these effects to the deviations in fundamental water properties as pore diameter decreases. In particular, these effects are most notable in SBA-15 with a 4-nm pore where the changes in water properties may be responsible for the enhanced Cu mobility, and therefore, faster $\mathrm{Cu}$ adsorption kinetics.
\end{abstract}

Keywords: Nano-scale confinement, Adsorption isotherm, Adsorption kinetics, Mesoporous silica

\section{Introduction}

Developing a better understanding of the chemistry at mineral surfaces is critical to predict the fate and transport of chemical species in soils, sediments, and in porous rocks [1]. Interfacial processes, taking place at the atomic scale: $\sim 10^{-10} \mathrm{~m}$ can manifest all the way to the scale of planet Earth: $\sim 10^{7} \mathrm{~m}$, and the chemistry at surfaces depend on the spatial environment of the surface [2]. Nano-scale confined domains are ubiquitous in the environment and exist in tight rocks (i.e. shale), where large fraction of pores are in the nano-scale range $[2,3]$. These domains have been recognized as an important factor in the selective permeability of tight rocks, a phenomenon largely attributed to the compressed electrical double layer at the water-solid interface as the pores decrease in size [2]. These nano-scale domains can be defined as microporous $(<2 \mathrm{~nm}$ pore diameter), mesoporous (2-50 $\mathrm{nm}$ pore diameter), and macroporous

*Correspondence: agilgen@sandia.gov

Geochemistry Department, Sandia National Laboratories, 1515 Eubank Blvd SE, Albuquerque, NM 87123, USA
( $>50 \mathrm{~nm}$ pore diameter) $[4,5]$. When fluids reside in these nano-pores, the observed thermodynamic properties of these systems deviate from those measured in bulk non-confined phases [6]. Previous research has shown, that with decreasing pore size, the fundamental properties of water change, which is expected to affect the adsorption of ions at mineral-water interfaces. Examples of these deviations in water properties include a decrease in the dielectric constant (as much as a $50 \%$ decrease with a $1.2 \mathrm{~nm}$ pore) $[7,8]$, density, and surface tension when the pore size is less than $5 \mathrm{~nm}$ [9]. These deviations are largely attributed to the high ratio of mineral-surfacebound (structured) water in nano-scale confined systems relative to bulk water [9].

Stimulated by the advances in the nanotechnology industry, nanogeochemistry has emerged as an active field of research and has led to numerous observations of size-dependent phenomena, including metal adsorption on mineral surfaces [2]. Propagated from changes in water properties, an observed decrease in the solvation energies and an increase in the formation of inner-sphere

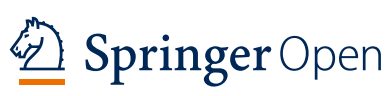

(c) National Technology of Engineering Solutions of Sandia, LLC 2018. This article is distributed under the terms of the Creative Commons Attribution 4.0 International License (http://creativecommons.org/licenses/by/4.0/), which permits unrestricted use, distribution, and reproduction in any medium, provided you give appropriate credit to the original author(s) and the source, provide a link to the Creative Commons license, and indicate if changes were made. The Creative Commons Public Domain Dedication waiver (http://creativecommons.org/publicdomain/zero/1.0/) applies to the data made available in this article, unless otherwise stated. 
complexes of metal cations can lead to enhanced adsorption $[2,10,11]$. Research has demonstrated these effects, showing an enhanced adsorption of arsenic (As) on ordered mesoporous alumina compared to non-porous activated alumina [12], and enhanced copper $(\mathrm{Cu})$ and uranium $(\mathrm{U})$ adsorption with decreasing hematite particle size [13, 14]. Furthermore, the adsorption mode for various adsorbed metals on zeolites with nanopores changed from outer sphere to inner sphere as the pore became smaller [15-17]. The adsorption of $\mathrm{Cu}$ on zeolites with narrow pores $(0.26-0.74 \mathrm{~nm})$ has been investigated with electron paramagnetic resonance spectroscopy and demonstrated an enhanced adsorption and increased inner sphere coordination in the zeolites with the smallest pores [15]. While these studies have illustrated the deviation in thermodynamic properties when mineral particles are limited to nano-scale, using natural mineral surfaces (i.e. hematite) or compared porous versus nonporous material, there has yet to be a study that takes a systematic approach to evaluate the adsorption properties of metal cations as a function of discrete incremental changes in the pore size.

In this study, the adsorption of $\mathrm{Cu}^{2+}$ was evaluated on mesoporous silica. Copper was chosen as an analyte because it is an important naturally-occurring trace element with abundance in the Earth's crust of $50 \mathrm{mg} \mathrm{kg}-1$ [18]. Copper is mined for its wide use in industrial applications, and as a result, can reach toxic concentrations in environmental systems [18-22]. At trace concentrations, $\mathrm{Cu}$ is essential for life, and is involved in many enzymatic reactions in mammals [18]. Industrially, $\mathrm{Cu}$ has applications in the electrical industry, in the production of alloys, as a catalysis, and much more $[18,19]$. As a result, the total anthropogenic discharge ranges from 35,000 to 90,000 metric tons per year [18]. Therefore, $\mathrm{Cu}$ is a common environmental pollutant where most of the $\mathrm{Cu}$ release is resulting from acid mine drainage and landfill leachates [19]. Understanding the adsorption properties of $\mathrm{Cu}$ and how the adsorption properties are impacted by nano-scale confinement is important in broadening our understanding of the fate and transport of $\mathrm{Cu}$ in a variety of complex environmental and geological systems. Additionally, using $\mathrm{Cu}^{2+}$ to probe the reactivity of confined interfaces, allowed us to quantify size-dependent behavior. Previous research has investigated the adsorption of $\mathrm{Cu}^{2+}$ on functionalized ordered mesoporous silica and alumina to assess $\mathrm{Cu}^{2+}$ removal for water treatment purposes [21-23]. Adsorption was significantly enhanced by the addition of functional groups $\mathrm{N}$-[3-(trimethoxysilyl) propyl]-ethylenediamine, from $0.036 \mathrm{mmol} \mathrm{Cu} \mathrm{g}^{-1}$ on unmodified silica to $0.261 \mathrm{mmol} \mathrm{Cu} \mathrm{g}{ }^{-1}$ on functionalized silica [22]. Modifying the silica substrate allowed for significant removal of $\mathrm{Cu}^{2+}$ from aqueous solution, but in doing so, the pore geometry, volume, and reactivity were altered; and no longer represented an environmentally equivalent (e.g. silicate) system. To evaluate the effects of nano-scale confinement with environmentally relevant reactive surfaces, we focused on unmodified mesoporous silica to present the first study, to our knowledge, that directly investigated the impact of pore size on the $\mathrm{Cu}^{2+}$ adsorption kinetics and uptake.

Ordered mesoporous silica is an ideal candidate to assess the impacts of nano-scale confinement on the adsorption of $\mathrm{Cu}^{2+}$. These materials are synthetically produced via a surfactant template, creating chemically stable high surface area structures with uniform pores and a narrow distribution of pore diameters [23]. These synthetic mesoporous materials are representative of the reactive surface sites typical on mineral surfaces, containing silanol functional groups (i.e. silicates) [24]. For our investigations, we utilized three analogues mesoporous silica substrates (SBA-15) with different size pore diameters, $8 \mathrm{~nm}$ (SBA-15-8), $6 \mathrm{~nm}$ (SBA-15-6), and $4 \mathrm{~nm}$ (SBA15-4) diameter, all having cylindrical pore geometry. These SBA-15 siliceous materials are produced by templating triblock copolymers to create a two-dimensional hexagonal array of non-intersecting cylindrical pores [25, $26]$. This range of pore diameters $(8,6$, and $4 \mathrm{~nm})$ represents the scale at which nano-scale confinement effects have been determined to be most significant $[8,9]$. We hypothesized that the adsorption of $\mathrm{Cu}^{2+}$ on mesoporous silica is pore size dependent, and suspect, as pore size decrease and confined water properties emerge, $\mathrm{Cu}^{2+}$ adsorption will be enhanced.

The goal of this study was to systematically assess the surface complexation of $\mathrm{Cu}^{2+}$ under nano-scale confinement in model mesoporous materials using batch adsorption isotherms and kinetics studies. The adsorption isotherms were fit to adsorption isotherm models (Langmuir, Freundlich, and Dubinin-Radushkevich) to extract adsorption parameters, and pseudo-first-order kinetics model to extract rate constants. This data was used to evaluate the impact of nano-scale confinement on the surface area normalized adsorptive behavior of $\mathrm{Cu}^{2+}$ on mesoporous silica.

\section{Experimental section \\ General}

All reagents used for batch adsorption studies were reagent grade or higher, including copper(II) nitrate trihydrate $\left(\mathrm{Cu}\left(\mathrm{NO}_{3}\right)_{2} \cdot 3 \mathrm{H}_{2} \mathrm{O}\right)$, ammonium nitrate $\left(\mathrm{NH}_{4} \mathrm{NO}_{3}\right)$, nitric acid $\left(\mathrm{HNO}_{3}\right)$, and ammonium hydroxide $\left(\mathrm{NH}_{4} \mathrm{OH}\right)$ (Sigma-Aldrich, St. Louis, MO). Ultrapure $\mathrm{HNO}_{3}$ (ULTREX II, J. T. Baker, Thermo Fisher Scientific, Waltham, MA) was used for dilutions and sample preservation. Aqueous concentrations of $\mathrm{Cu}^{2+}$ were quantified 
via inductively coupled plasma mass spectrometer (ICPMS) (NexION 350D, Perkin Elmer, Waltham, MA). All gasses and cryogenic liquids used for ICP-MS analysis and Brunauer-Emmett-Teller (BET) surface area analysis were ultrapure quality grade (Matheson, Basking Ridge, $\mathrm{NJ}$ ) including liquid and gaseous argon (Ar) and nitrogen $\left(\mathrm{N}_{2}\right)$, along with helium $(\mathrm{He})$ gas. All mesoporous materials were purchased from Sigma Aldrich (Sigma Aldrich, St. Louis, MO). These materials included SBA-15-8, SBA-15-6, SBA-16-4 correspond to hexagonally ordered cylindrical pores with diameters of 4,6 , and $8 \mathrm{~nm}$. MilliQ $\mathrm{H}_{2} \mathrm{O}$ (Barnstead NANOpure Diamond, resistivity of $18.2 \mathrm{M} \Omega * \mathrm{~cm}, 0.2 \mu \mathrm{m}$ filtered and UV irradiated) was used in the preparation of all solutions and suspensions.

\section{BET surface area and pore size determination}

The BET surface area for each mesoporous material was obtained using two different BET surface area analyzers, an ASAP 2020 (Micrometrics, Norcross, GA) and a TriStar (Micrometrics, Norcross, GA). The procedure on both instruments was the same. Approximately $200 \mathrm{mg}$ of dry mesoporous material was transferred into a tarred BET tube equipped with an airtight cap. The samples were degassed at $300{ }^{\circ} \mathrm{C}$ for $4 \mathrm{~h}$ and backfilled with inert He gas. Following the sample degas, the mass of the sample was updated to account for mass changes in the resulting from the degas. Next, the liquid $\mathrm{N}_{2}$ Dewar was filled, a thermal jacket was placed on the BET tube, the tube was placed in the sample holder, and the analysis was started. The surface area analyzer determined the BET surface area and the non-local density functional theory (NLDFT) method was used to determine pore diameter and volume for each SBA-15 substrate [26, 27].

\section{Thermogravimetric analysis}

Thermogravimetric analysis (TGA; Thermal Analysis, SDT Q600, New Castle, DE) was performed on SBA15-4, SBA-15-6, and SBA-15-8 to estimate the hydroxyl group density. Prior to analysis each silica material was thoroughly rinsed and dried. Briefly, approximately $600 \mathrm{mg}$ of mesoporous material was added to centrifuge bottle with $200 \mathrm{~mL}$ of Milli-Q water and mixed on a shaker table (Orbital-Genie, Scientific Industries, INC, Bohemia, New York). Following shaking for $24 \mathrm{~h}$ the materials were filtered $(45 \mu \mathrm{m}$, Pall Corporation, Ann Arbor, MI), and rinsed with Milli-Q water and suspended in $200 \mathrm{~mL}$ of Milli-Q water. This process was repeated two additional times. Following the final rinse, the mesoporous materials were transferred to a scintillation vial and placed in the oven $\left(45^{\circ} \mathrm{C}\right)$ for at least $48 \mathrm{~h}$. Once dry, roughly $10 \mathrm{mg}$ silica was transferred to a tarred TGA crucible (100 $\mu \mathrm{L}$, Robocasting, Albuquerque, NM) and placed in the TGA furnace. The flow rate of Ar was
$100 \mathrm{~mL} / \mathrm{min}$ with an experimental sequence: (i) $20 \mathrm{~min}$ room temperature isothermal to equilibrate, (ii) ramp temperature at $10{ }^{\circ} \mathrm{C} / \mathrm{min}$ from room temperature to $1000^{\circ} \mathrm{C}$.

\section{Batch adsorption and adsorption isotherms}

Batch adsorption isotherm experiments were performed to evaluate the adsorption of $\mathrm{Cu}^{2+}$ on SBA-15-8, SBA15-6, and SBA-15-4. The SBA-15 materials were rinsed prior to use, as described above (same method as TGA). Following being rinsed and dried, approximately $20 \mathrm{mg}$ was weighed out and transferred to a $50 \mathrm{~mL}$ centrifuge tube with $5 \mathrm{~mL}$ of $10 \mathrm{mM} \mathrm{NH}_{4} \mathrm{NO}_{3}$ and rehydrated for at least $24 \mathrm{~h}$. The electrolyte, $\mathrm{NH}_{4} \mathrm{NO}_{3}$, was chosen as the background electrolyte to prevent adding any metal cationic species to compete for surface adsorption sites. Following $24 \mathrm{~h}, \mathrm{Cu}\left(\mathrm{NO}_{3}\right)_{2}$ was added to each $50 \mathrm{~mL}$ centrifuge tube with a concentration of $\mathrm{Cu}^{2+}$ ranging from 5 to $300 \mu \mathrm{M}$ from a stock $\mathrm{Cu}\left(\mathrm{NO}_{3}\right)_{2}$ solution and brought up to $10 \mathrm{~mL}$ total volume with Milli-Q water. The $\mathrm{pH}$ was adjusted using dilute solutions of $\mathrm{HNO}_{3}$ and $\mathrm{NH}_{4} \mathrm{OH}$ to achieve a final $\mathrm{pH}$ of $6.0 \pm 0.1$ and final ionic strength of $10 \pm 1 \mathrm{mM}$. Under these experimental conditions the dominant aqueous $\mathrm{Cu}$ species is $\mathrm{Cu}^{2+}$ (roughly 96\%, estimated using Visual MINTEQ 3.1) [28]. A detailed $\mathrm{Cu}$ speciation diagram is provided in Additional file 1: Figure S1. The contents were mixed via shaker table for $24 \mathrm{~h}$. After mixing, the samples were centrifuged (Allegra 25R, Beckman Coulter, Indianapolis, IN) at $3000 \mathrm{rpm}$ for $10 \mathrm{~min}$ to separate the solid mesoporous silica from the supernatant electrolyte solution. To fully separate the phases and remove any suspended mesoporous silica, the supernatant was transferred to a $10 \mathrm{~mL}$ syringe fit with a $0.20 \mu \mathrm{m}$ nylon filter (Millex-GN, EMD Millipore, Billerica, MA) and the contents pushed through to a $15 \mathrm{~mL}$ centrifuge tube. Ultra pure $6 \mathrm{M} \mathrm{HNO}_{3}$ was added to each sample $\left(10 \mu \mathrm{L} \mathrm{mL}^{-1}\right)$ for sample preservation to keep $\mathrm{Cu}^{2+}$ cations from hydrolyzing and precipitating.

The samples were diluted to a concentration range suitable for $\mathrm{Cu}$ quantification via ICP-MS (10-2000 ppb). Dilutions were performed using Ultrapure $2 \% \mathrm{HNO}_{3}$ by a factor of 2, 5, 10, or 50 and kept in the refrigerator until the ICP-MS analysis. The experimental data was fit to three adsorption isotherm models: Langmuir, Freundlich, and Dubinin-Radushkevich.

\section{Langmuir adsorption isotherm}

The Langmuir adsorption model represents homogenous adsorption behavior in which the adsorbate occurs at definite sites and does not exceed monolayer coverage [29, 30]. In this model, adsorption occurs when an adsorbate molecule overcomes a constant adsorption activation energy, and assumes a finite number of surface sites that 
are all equally probable for adsorption [29, 31, 32]. The Langmuir adsorption equation is shown in Eq. 1 [29, 33],

$$
q_{e}=\frac{K_{L} q_{m-L}[\mathrm{Cu}]_{e q}}{1+K_{L}[\mathrm{Cu}]_{e q}}
$$

where $\mathrm{K}_{\mathrm{L}}$ is the Langmuir constant $(\mathrm{L} / \mu \mathrm{mol})$, and $\mathrm{q}_{\mathrm{m}-\mathrm{L}}$ is the surface area normalized maximum adsorption of $\mathrm{Cu}\left(\mu \mathrm{mol} / \mathrm{m}^{2}\right)$. The experimental data was fit to the linear form of the Langmuir adsorption isotherm is shown in Eq. 2.

$$
\frac{1}{q_{e}}=\frac{1}{q_{m-L}}+\frac{1}{K_{L} q_{m}[C u]_{e q}}
$$

From the Langmuir adsorption model we estimated the dimensionless equilibrium parameter $\left(R_{L}\right)$ shown in Eq. 3.

$$
R_{L}=\frac{1}{1+K_{L}[\mathrm{Cu}]_{\text {inital }}}
$$

The equilibrium parameter provides an understanding of the favorability of the adsorption as a function of the initial concentration of adsorbate, when $R_{L}>1$ the adsorption is unfavorable, $0<\mathrm{R}_{\mathrm{L}}<1$ the adsorption is favorable, and when $\mathrm{R}=0$ the adsorption is irreversible $[30,34]$.

\section{Freundlich adsorption isotherm}

In contrast to the Langmuir adsorption model, in which surface does not exceed monolayer coverage of the adsorbate, the Freundlich adsorption model describes heterogeneous adsorption behavior in which the adsorption coverage can exceed monolayer coverage [35]. The Freundlich adsorption equation is shown in Eq. 4,

$$
q_{e}=K_{F}[C u]_{e q}^{\frac{1}{n}}
$$

where $K_{F}$ is related to the surface area normalized maximum adsorption of $\mathrm{Cu}\left(\mu \mathrm{mol} / \mathrm{m}^{2}\right)$ and $\mathrm{n}$ is dimensionless term that indicates the extent of surface heterogeneity. The linear form of the Freundlich adsorption model is shown in Eq. 5.

$$
\log q_{e}=\log K_{F}+\frac{1}{n} \log [C u]_{e q}
$$

It should be noted that the Freundlich isotherm does not accurately determine the absolute maximum adsorbed $\mathrm{Cu}$ [36]. This is due to the fact that $\mathrm{q}_{\mathrm{e}}$ is directly proportional to $\left[\mathrm{Cu}^{2+}\right]_{\mathrm{eq}}$, and therefore $\mathrm{q}_{\mathrm{e}}$ will increase as $\left[\mathrm{Cu}^{2+}\right]_{\text {eq }}$ increases. Yet, the $K_{\mathrm{F}}$ value can be used as a qualitative comparison to assess the relative adsorption maximum values of $\mathrm{Cu}$ on mesoporous silica surfaces.

\section{Dubinin-Radushkevich adsorption isotherm}

The final adsorption isotherm considered to evaluate the adsorption of $\mathrm{Cu}$ on mesoporous materials was the Dubinin-Radushkevich adsorption isotherm. This empirical adsorption model was first used to describe a pore filling mechanism and is generally used to express adsorption processes that occur via homogeneous and heterogeneous processes [37]. Equation 6 is the DubininRadushkevich adsorption model,

$$
q_{e}=q_{m-D R} * e^{-k_{D R} \varepsilon^{2}}
$$

where $\mathrm{q}_{\mathrm{m}-\mathrm{DR}}$ is the maximum surface area normalized amount of $\mathrm{Cu}$ adsorbed on the mesoporous surfaces $\left(\mu \mathrm{mol} / \mathrm{m}^{2}\right)$, and $\mathrm{k}_{\mathrm{DR}}$ is proportional to the adsorption energy $\left(\mathrm{mol}^{2} / \mathrm{kJ}^{2}\right)$. The Polanyi potential, $\varepsilon$, is defined by Eq. 7 [38],

$$
\varepsilon=R T * \ln \left(1+\frac{1}{[\mathrm{Cu}]_{e q}}\right)
$$

where $\mathrm{R}$ is the gas constant $\left(\mathrm{kJ} / \mathrm{K}^{*} \mathrm{~mol}\right)$ and $\mathrm{T}$ is the temperature (K). The linear form of the Dubinin-Radushkevich adsorption model is shown by Eq. 8 .

$$
\ln q_{e}=\ln q_{m-D R}-k_{D R} \varepsilon^{2}
$$

The fitting parameters $\mathrm{q}_{\mathrm{m}-\mathrm{DR}}$ and $\mathrm{k}_{\mathrm{DR}}$ are determined by the intercept and slope, respectively, of a the linear line when plotted $\ln \left(\mathrm{q}_{\mathrm{e}}\right)$ versus $\varepsilon^{2}$.

\section{Kinetic studies}

Kinetic studies were performed to determine the rate law of the $\mathrm{Cu}$ adsorption on mesoporous materials, and to quantify the effect of nano-scale confinement on the adsorption rates. For these studies, $100 \mathrm{mg}$ of hydrated mesoporous silica was transferred to a $100 \mathrm{~mL}$ beaker with $25 \mathrm{~mL}$ of $10 \mathrm{mM} \mathrm{NH}_{4} \mathrm{NO}_{3}$, a stir bar set to vigorously mix the solution at $300 \mathrm{rpm}$ and enough DI water to achieve a final volume of $50 \mathrm{~mL}$. The solution $\mathrm{pH}$ was adjusted using $\mathrm{HNO}_{3}$ and $\mathrm{NH}_{4} \mathrm{OH}$ to a $\mathrm{pH}=6.0 \pm 0.1$. Following the $\mathrm{pH}$ adjustment, a known amount of $\mathrm{Cu}^{2+}$ was spiked into the solution $(5-10 \mu \mathrm{M} \mathrm{Cu})$. The time and $\mathrm{pH}$ were recorded at this point and represented time $=0$. The $\mathrm{pH}$ was continuously monitored by the $\mathrm{pH}$ probe as $3 \mathrm{~mL}$ aliquots were removed at set time points during the experiment and transferred to a $10 \mathrm{~mL}$ syringe and filtered into a $15 \mathrm{~mL}$ centrifuge tube containing $30 \mu \mathrm{L}$ ultra pure $6 \mathrm{M} \mathrm{HNO}_{3}$. The kinetic studies ran for $6 \mathrm{~h}$ to 
establish an equilibrium value for adsorbed $\mathrm{Cu}\left(\mathrm{q}_{\mathrm{e}}\right)$. This procedure was repeated at three concentrations of $\mathrm{Cu}^{2+}$ for each silica material.

Following the kinetic experiments, the samples representing unique time points (minutes) were diluted by a factor of 3 with Ultrapure $2 \% \mathrm{HNO}_{3}$ for Cu quantification by ICP-MS. The diluted samples were kept in the refrigerator until sample analysis for $\mathrm{Cu}$.

\section{Pseudo-first-order adsorption kinetics}

Batch kinetic adsorption studies were performed and fit to a pseudo-first-order reaction model. The rate constants for the adsorption of $\mathrm{Cu}$ on SBA-15-4, SBA-15-6, and SBA-15-8 were determined from the model fit. The pseudo-first-order reactions occur when the reaction is second order, however, one of the reactants is in excess and largely remains unchanged [39]. In this case, three different dilute initial $\mathrm{Cu}^{2+}$ concentrations were reacted with $100 \mathrm{mg}$ of mesoporous material. This is consistent with the fact that we had low $\mathrm{Cu}^{2+}$ concentrations and high silica reactive surface area.

The rate law representing a pseudo-first-order reaction is shown in Eq. 9.

$$
\text { Rate }=k *[\text { ReactiveSurface }][\mathrm{Cu}]
$$

Since the concentration of the reactive surface is in excess and essentially remains unchanged throughout the reaction coordinate, the rate equation can be reduced to Eq. 10:

$$
\text { Rate }=k^{\prime}[\mathrm{Cu}]
$$

where $\mathrm{k}^{\prime}$ is related to $\mathrm{k}$ and the reactive surface concertation [39]. The integrated pseudo-first-order rate equation is shown in Eq. 11,

$$
\ln \left(q_{e}-q_{t}\right)=\ln q_{e}-k t
$$

where, $\mathrm{q}_{\mathrm{e}}$ is the equilibrium adsorbed $\mathrm{Cu}, q_{t}$ is the adsorbed $\mathrm{Cu}$ at time $=t, k$ is the pseudo-first-order rate constant $\left(\mathrm{min}^{-1}\right)$, and $t$ is time ( $\left.\mathrm{min}\right)$.

\section{Copper analysis}

The $\mathrm{Cu}$ content in each sample was quantified by ICPMS as described previously [40]. Briefly, standards were prepared with concentrations ranging from 10 to $2000 \mathrm{ppb}$ and used to generate a calibration curve to determine concentration of $\mathrm{Cu}$ in each sample from intensity. The stock solutions and reference solutions of identical experimental matrix (in the absence of SBA-15) were analyzed with the samples. The surface area normalized amount of adsorbed $\mathrm{Cu}(\mathrm{q})$, in $\mu \mathrm{mol} / \mathrm{m}^{2}$, was determined from Eq. 12:

$$
q=\frac{\left([\mathrm{Cu}]_{i}-[\mathrm{Cu}]_{e q}\right) * v}{(m * A)}
$$

where $[\mathrm{Cu}]_{\mathrm{i}}$ and $[\mathrm{Cu}]_{\mathrm{eq}}$ are the initial and equilibrium concentrations (measured by ICP-MS) of $\mathrm{Cu}$ in $\mu \mathrm{M}, v$ is the volume in $\mathrm{L}, m$ is the mass of mesoporous material in $\mathrm{g}$, and $A$ is the surface area of that mesoporous materials as determined by BET surface area analyzer in $\mathrm{m}^{2} / \mathrm{g}$. The $q$ values were then used to determine adsorption isotherm fits and kinetic rates of $\mathrm{Cu}$ adsorption on SBA-158, SBA-15-6, and SBA-15-4 substrates.

\section{Results and discussion}

From studies investigating $\mathrm{Cu}$ adsorption on SBA-158, SBA-15-6, and SBA-15-4, we systemically evaluated the effects of nano-scale confinement. The sum of these effects provide insight into how nano-scale confinement can enhance metal adsorption in meso- and nano-porous materials.

\section{BET surface area and pore size distribution}

The BET surface areas, pore diameters, pore volumes, and percent pore surface area were determined for each SBA-15 used in this study. The results are summarized in Table 1. Surface area and pore size distributions were evaluated on two different BET analyzers as the experimental surface area trend did not agree with the surface areas provided by the supplier. However, the average pore diameter trend did agree with the supplier reported value. We observed a decrease in the total BET surface areas of $661 \pm 5 \mathrm{~m}^{2} / \mathrm{g}, 603 \pm 16$, and $582 \pm 13 \mathrm{~m}^{2} / \mathrm{g}$ as the pore size decreased from 7.0 $\pm 0.3,5.2 \pm 0.2,4.4 \pm 0.1 \mathrm{~nm}$ for SBA-15-8, SBA-15-6, and SBA-15-4, respectively. Furthermore, a recent study demonstrated a similar trend

Table 1 Pore size and BET surface area of SBA-15-8, SBA-15-6, and SBA-15-4

\begin{tabular}{llllll}
\hline Material & Pore size $(\mathbf{n m})$ & $\begin{array}{l}\text { BET surface area } \\
\left(\mathbf{m}^{2} / \mathbf{g}\right)\end{array}$ & Pore volume $\left(\mathbf{c m}^{\mathbf{3}} \mathbf{/ g}\right)$ & $\begin{array}{l}\text { \% surface area } \\
\text { from pores }\end{array}$ & $\begin{array}{l}-\mathbf{O H}-\text { density } \\
\left(-\mathbf{O H} / \mathbf{n m} \mathbf{2}^{\mathbf{2}}\right)\end{array}$ \\
\hline SBA-15-8 & $7.0 \pm 0.3$ & $661 \pm 5$ & $1.21 \pm 0.03$ & $89 \pm 6$ & $1.8 \pm 0.2$ \\
SBA-15-6 & $5.2 \pm 0.2$ & $603 \pm 16$ & $0.87 \pm 0.03$ & $80 \pm 5$ & $1.9 \pm 0.2$ \\
SBA-15-4 & $4.4 \pm 0.1$ & $580 \pm 13$ & $0.67 \pm 0.04$ & $75 \pm 6$ & $2.3 \pm 0.2$ \\
\hline
\end{tabular}

The BET surface areas were used to calculate the surface area normalized $\mathrm{Cu}$ adsorption 
with synthesized SBA-15 substrate, as the pore diameter decreased, the BET surface area decreased as well [25]. The experimental values of the BET surfaces areas reported in Table 1 were used to normalize the adsorption of $\mathrm{Cu}$ to the total surface area of the substrate.

The pore diameters were determined using the NLDFT method [26, 27]. The pore size distribution plots are shown in Additional file 1: Figure S2. The mesopore diameter is relatively narrow distribution resulting in average pore diameters and volumes reported in Table 1. As reported in previous pore size distributions of SBA15 materials, there are micropores present as well [26, 41, 42]. The mesopores exist in the main channels as templated from the removal of the calcined surfactant, whereas the micropores co-exist due to intrawall pores that develop as a consequence of the removal of the surfactant template creating structural irregularities [43]. This can be seen in the SBA-15-4 plot (Additional file 1: Figure S2), in which the pore size distribution is bimodal with peaks centered around 4.4 and $2 \mathrm{~nm}$. In contrast, the SBA-15-8 (Additional file 1: Figure S2) shows a primary contribution from the mesopores centered around $8 \mathrm{~nm}$, and a small contribution of micropores centered around $2 \mathrm{~nm}$. For this study, we considered the average pore size diameter to assess the effects of nano-scale confinement. While the observed effects may be attributed to the increased presence of micropores, the micropores are defined by one data point and we believe appropriate nano-scale confinement conclusions can be drawn from adsorption deviations of $\mathrm{Cu}$ with these substrates.

\section{Thermogravimetric analysis}

The results of the TGA analysis are shown in Fig. 1. This plot shows the percent mass loss of SBA-15-8, SBA-156, and SBA-15-4 as a function of temperature. From the TGA plots the surface - $\mathrm{OH}$ group density was estimated and reported in Table 1 . The first observable mass loss feature in Fig. 1 between 20 and $200{ }^{\circ} \mathrm{C}$ was attributed to presence of physisorbed water [44]. Following the water loss, the mass loss from 200 to $1000{ }^{\circ} \mathrm{C}$ was primarily attributed to surface dehydroxylation [44]. There are likely to be internal $-\mathrm{OH}$ groups, however, these groups are not typically dehydroxylated until $>900{ }^{\circ} \mathrm{C}$ [44]. As a result, the average $-\mathrm{OH}$ surface densities $\left(-\mathrm{OH} / \mathrm{nm}^{2}\right)$ were determined to be $1.8 \pm 0.2,1.9 \pm 0.2,2.1 \pm 0.2$ for SBA-15-8, SBA-15-6, and SBA-15-4, respectively. These $-\mathrm{OH}$ surface densities strongly agree with previously reported accessible $-\mathrm{OH}$ densities of SBA-15 of 1.7 $\mathrm{OH} / \mathrm{nm}^{2}[45,46]$. The $-\mathrm{OH}$ density also corresponds with the observed wettability, as seen by the magnitude of desorption of physisorbed water. An increase in the $-\mathrm{OH}$ density would lead to a more hydrophilic surface.

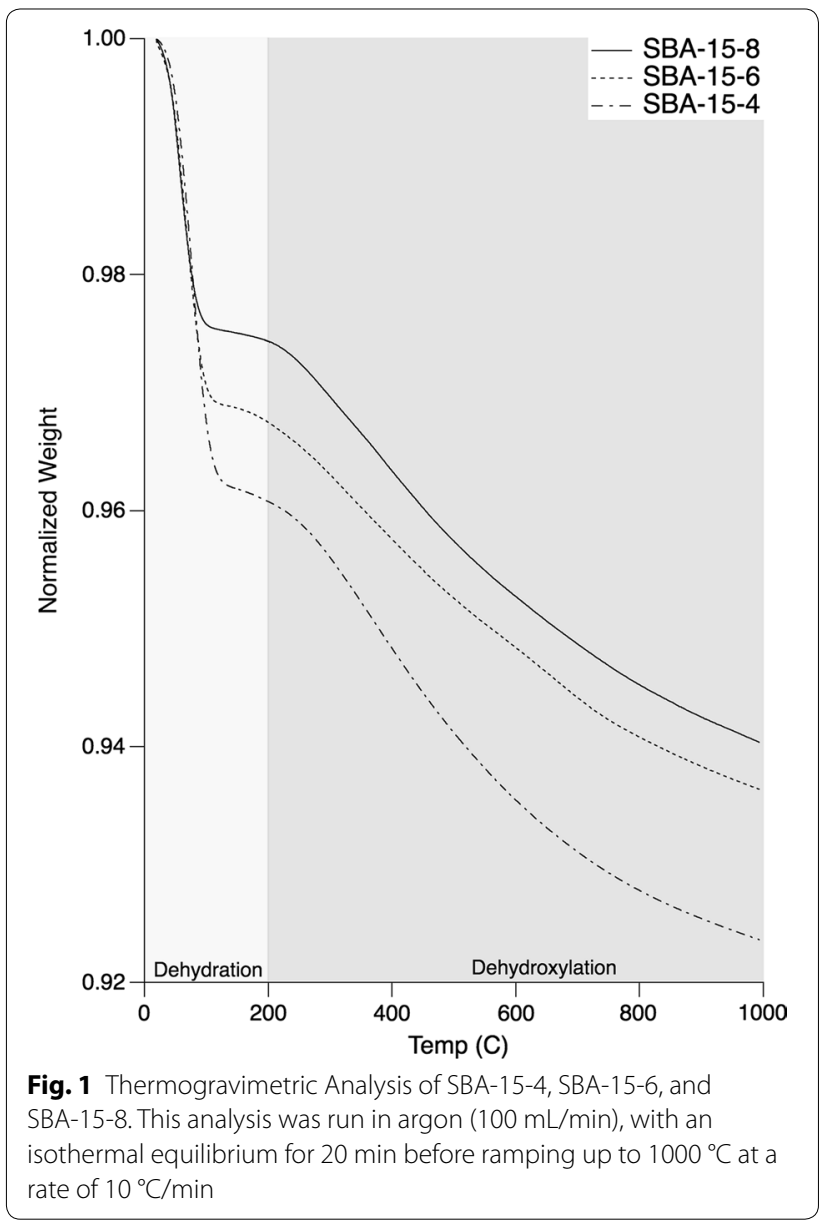

The $-\mathrm{OH}$ group density appears to inversely correlate with the pore size.

\section{$\mathrm{Cu}$ adsorption isotherms and nano-scale confinement effects}

The adsorption of $\mathrm{Cu}$ on SBA-15-8, SBA-15-6, and SBA-15-4 are shown in Fig. 2, where the amount of $\mathrm{Cu}$ $\left(\mu \mathrm{mol} \mathrm{m}{ }^{-2}\right)$ adsorbed was plotted versus the equilibrium concentration of $\mathrm{Cu}^{2+}$. The data was fit to adsorption isotherm models: Langmuir [29], Freundlich [35], and Dubinin-Radushkevich [37]. Copper adsorption onto the surface of SBA-15 was poor overall, with the maximum measured surface loading of $\mathrm{Cu}$ of $0.020 \pm 0.001$, $0.019 \pm 0.002$, and $0.039 \pm 0.002 \mu \mathrm{mol} \mathrm{m}{ }^{-2}$ of substrate for SBA-15-8, SBA-15-6, and SBA-15-4, respectively, when $[\mathrm{Cu}]_{\text {initial }}=300 \mu \mathrm{M}$. The maximum measured surface loading of $\mathrm{Cu}$ was equal within experimental error for SBA-15-8 and SBA-15-6, however for SBA-15-4, the maximum measured surface loading was nearly double. While we did observe differences in the surface $-\mathrm{OH}$ group densities (1.8 vs $2.1-\mathrm{OH} / \mathrm{nm}^{2}$ for SBA-15-8 and 


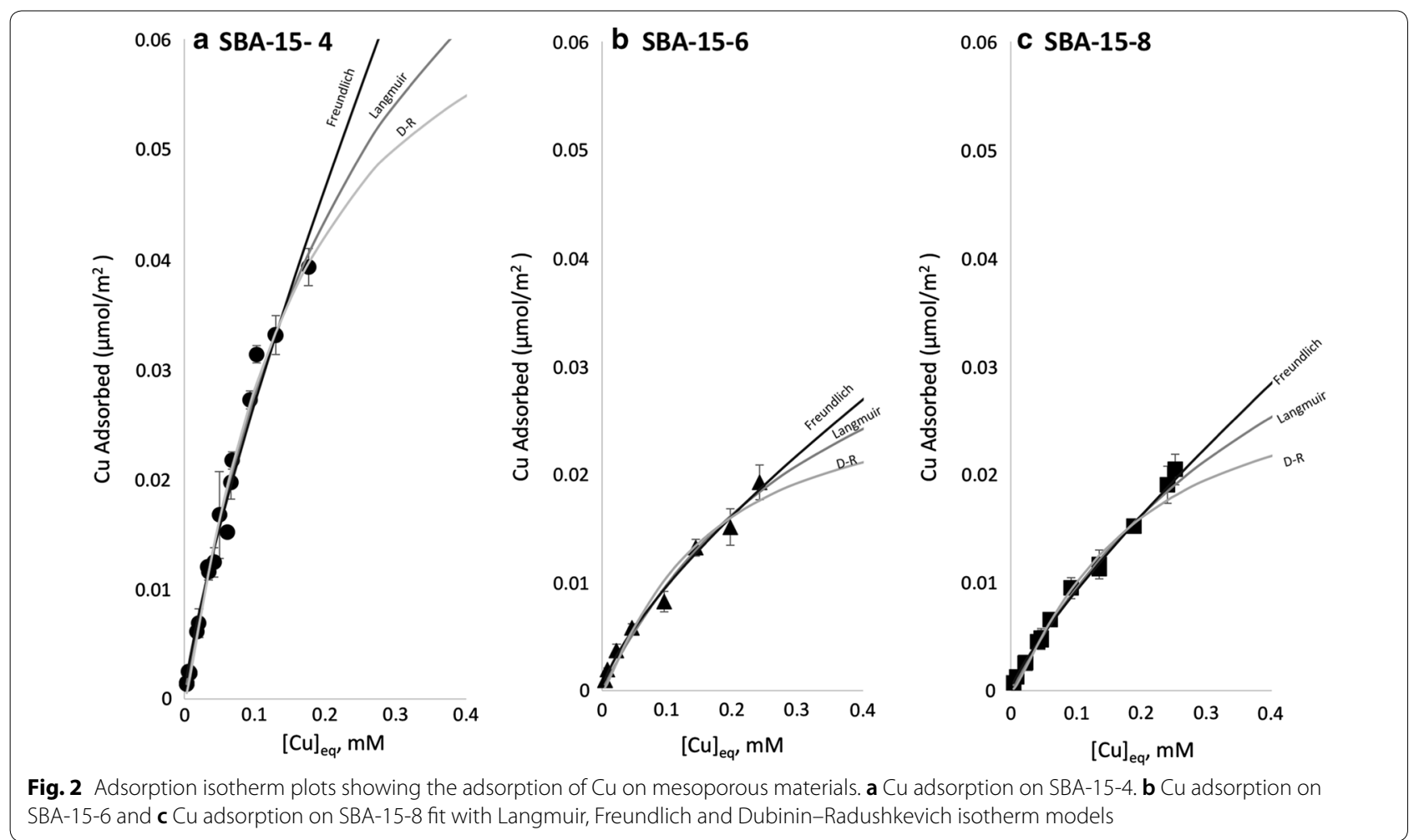

SBA-15-4), we believe those differences are not sufficient to explain the observed differences between SBA15-4 over SBA-15-6 and SBA-15-8. To add, the available reactive surface $-\mathrm{OH}$ sites remained in 100 -fold excess to the maximum $\mathrm{Cu}$ values all cases. Because the number of $-\mathrm{OH}$ groups remains in 100-fold excess over adsorbed $\mathrm{Cu}$ atoms, we believe that the observed differences in adsorption should be attributed to the effects of nano-scale confinement. Likewise, the estimated percent of occupied -OH surface sites (assuming mono-dentate inner-sphere $\mathrm{Cu}$ adsorption complex [19]) never exceed $1 \%$. These calculations may suggest that $\mathrm{Cu}$ requires a specific surface conformation of silanol groups to bind [46]. This hypothesis will be investigated by X-ray adsorption spectroscopic studies.
The adsorption of $\mathrm{Cu}$ was fit to Langmuir, Freundlich, and Dubinin-Radushkevich isotherms using IGOR Pro 7 curve fitting using equations representing each model. For these studies $\mathrm{pH}=6$ was chosen because $\mathrm{Cu}^{2+}$ is the dominant aqueous species (Additional file 1: Figure S1, $[\mathrm{Cu}]=0.1 \mathrm{mM}$ ), as well as our target initial concentrations of $\mathrm{Cu}^{2+}$ were below the solubility limit; however, at $[\mathrm{Cu}]_{\text {initial }}>0.3 \mathrm{mM}, \mathrm{Cu}$ began to precipitate. Further, $\mathrm{pH}=6$ was chosen to maximize the adsorption of $\mathrm{Cu}$, based on the previous adsorption studies which illustrated that $\mathrm{Cu}$ was poorly adsorbed onto amorphous silica at $\mathrm{pH}<6[19,20]$. For these reasons; (i) limited $\mathrm{Cu}$ solubility, (ii) relatively poor $\mathrm{Cu}$ adsorption, all three adsorption isotherms were close to being linear (Fig. 2), and could be fit with either of the three isotherm models,

Table 2 Fitting parameters obtained from the linear transformation of the data for Langmuir, Freundlich, and DubininRadushkevich adsorption models

\begin{tabular}{|c|c|c|c|c|c|c|c|c|c|}
\hline \multirow{2}{*}{$\begin{array}{l}\text { Material } \\
\text { Substrate }\end{array}$} & \multicolumn{3}{|l|}{ Langmuir fit } & \multicolumn{3}{|c|}{ Freundlich fit } & \multicolumn{3}{|c|}{ Dubinin-Radushkevich fit } \\
\hline & $\mathrm{K}_{\mathrm{L}}, \mathrm{L} / \mu \mathrm{mol}$ & $q_{m-L^{\prime}}, \mu \mathrm{mol} / \mathrm{m}^{2}$ & $r^{2}$ & $\mathrm{n}$ & $\mathrm{K}_{\mathrm{F}}\left(\mu \mathrm{mol} / \mathrm{m}^{2}\right)$ & $r^{2}$ & $\mathrm{~K}_{\mathrm{D}-\mathrm{R}^{\prime}} \mathrm{mol}^{2} / \mathrm{kJ}^{2}$ & $\mathrm{q}_{\mathrm{m}-\mathrm{DR}} \mu \mathrm{mol} / \mathrm{m}^{2}$ & $r^{2}$ \\
\hline SBA-15-8 & $2.0 \pm 0.4$ & $0.057 \pm 0.008$ & 0.996 & $1.23 \pm 0.03$ & $0.060 \pm 0.002$ & 0.998 & $3.4 \times 10^{-8} \pm 8 \times 10^{-9}$ & $0.0251 \pm 0.001$ & 0.962 \\
\hline SBA-15-6 & $2.7 \pm 0.6$ & $0.05 \pm 0.01$ & 0.996 & $1.36 \pm 0.08$ & $0.053 \pm 0.004$ & 0.990 & $3.0 \times 10^{-8} \pm 8 \times 10^{-9}$ & $0.024 \pm 0.002$ & 0.984 \\
\hline SBA-15-4 & $3.6 \pm 0.6$ & $0.10 \pm 0.01$ & 0.994 & $1.27 \pm 0.06$ & $0.17 \pm 0.01$ & 0.992 & $2.9 \times 10^{-8} \pm 8 \times 10^{-9}$ & $0.0622 \pm 0.002$ & 0.982 \\
\hline
\end{tabular}




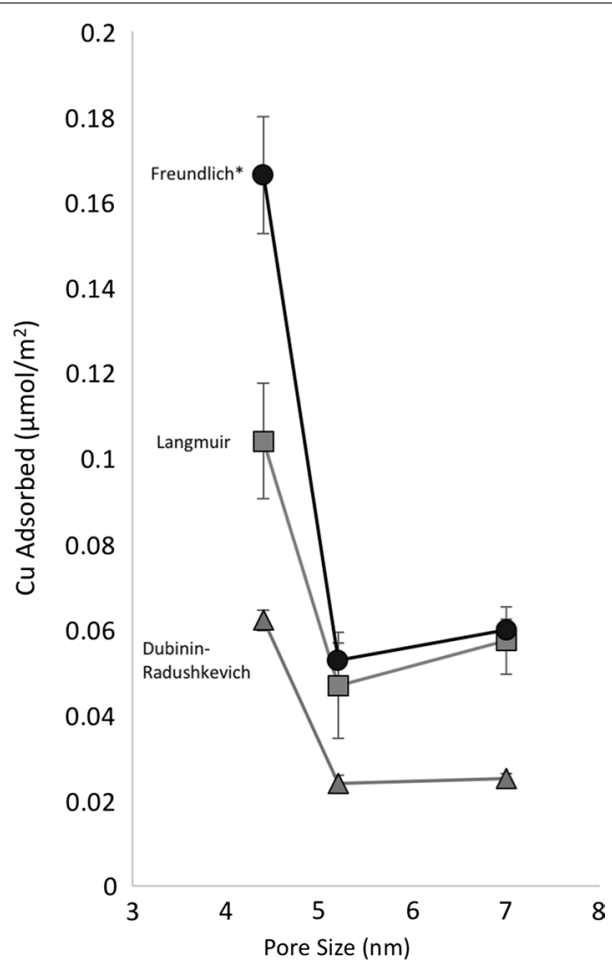

Fig. 3 Surface area normalized adsorption maximum values of $\mathrm{Cu}$ calculated from Langmuir, Freundlich, and Dubinin-Radushkevich isotherm models as a function of pore size. *Freundlich adsorption model does not provide an accurate absolute maximum adsorption value; however, can be used to assess relatively adsorption maximums

as seen from $r^{2}$ values $>96 \%$ (and most fits were $>99 \%$ ) in Table 2. The observed trends were consistent among each of the adsorption models. It was observed that SBA-15-4 had the largest uptake of $\mathrm{Cu}$ (normalized to the surface area), followed by SBA-15-6 and SBA-15-8; which were generally within experimental error as seen in Fig. 3 and Table 2. Figure 3 presents the surface area normalized adsorption maximum values as a function of pore size for each adsorption isotherm model. It is important to note, that as a result of the range limitation of the adsorption isotherm and low adsorption, the isotherms are limited to mostly the linear region. Because of this, the uncertainties of the maximum adsorption values are relatively large. Even so, the observed differences in the surface area normalized adsorption of $\mathrm{Cu}$ on silica with different pore sizes illustrates nano-scale confinement effects. These effects are quantified from the terms $\mathrm{q}_{\mathrm{m}-\mathrm{L}}, \mathrm{K}_{\mathrm{F}}$, and $\mathrm{q}_{\mathrm{m}-\mathrm{DR}}$; referring the model determined maximum adsorption value for Langmuir, Freundlich, and DubininRadushkevich isotherm, respectively. While the adsorption of $\mathrm{Cu}$ on SBA-15-8 and SBA-15-6 were within error (for Langmuir and Dubinin-Radushkevich) or slightly different (Freundlich), the adsorption of $\mathrm{Cu}$ on SBA-15-4 was significantly enhanced for all isotherm models. This observation agrees with previously reported results suggesting enhanced metal cation adsorption when pore sizes or particles are less than $5 \mathrm{~nm}[2,9]$.

An assessment of the qualitative adsorption parameters $\left(\mathrm{K}_{\mathrm{L}}, n\right.$, and $\left.\mathrm{K}_{\mathrm{D}-\mathrm{R}}\right)$ shows that the adsorption affinities are generally similar for all three silica materials $[29,35$, 37]. The qualitative adsorption parameter $K_{L}$ and $K_{D-R}$ $\left(K_{D-R}\right.$ term in inversely proportional to adsorption affinity) suggest the adsorption affinity in the Langmuir and Dubinin-Radushkevich isotherm models are pore size dependent, while $n$ has no pore size dependency trend as shown in Table 2. These terms qualitatively describe the adsorption affinity, suggesting there may be an increased adsorption affinity of $\mathrm{Cu}$ as the pore size decreases.

Additional information can be gleaned from the values of $\mathrm{K}_{\mathrm{L}}$. From the $\mathrm{K}_{\mathrm{L}}$ value, $\mathrm{R}_{\mathrm{L}}$ can be approximated from Eq. 3. A plot of $R_{L}$ versus $[\mathrm{Cu}]_{\text {initial }}$ (Additional file 1: Figure S3) estimates the reaction coordinate based upon differences in the $K_{L}$ values. The values of $R_{L}$ decrease with increasing $\mathrm{Cu}^{2+}$ concentration and remain between 1 and 0 . This shows, as $\mathrm{Cu}^{2+}$ increases in the system, surface sites become occupied, thus the surface reaction decreases, but remains favorable. It was also found that the $\mathrm{K}_{\mathrm{L}}$ for SBA-15-4 pore was the lowest, indicating the most rapid decay of the $R_{L}$ term as a function of $[\mathrm{Cu}]_{\text {initial }}$. At the maximum $[\mathrm{Cu}]_{\text {initial }}=0.3 \mathrm{mM}$, the $\mathrm{R}_{\mathrm{L}}$ values are $0.63,0.55$ and 0.48 for SBA-15-8, SBA-15-6, and SBA15-4, respectively. At the maximum adsorbed values of $\mathrm{Cu}$, only $1 \%$ of the total $-\mathrm{OH}$ groups were occupied. The reactive surface sites are in excess compared to $\mathrm{Cu}$ and therefore the reaction favors the formation of surface complexes. Because these values are between 1 and 0 , the surface adsorption reaction is still favorable; which suggests either, (i) the monolayer surface coverage has not reached a maximum value, or (ii) that multi-layer adsorption (i.e. dimerization, polymerization, or precipitation) occurs even at low surface coverages.

Additional work is planned to assess the coordination chemistry of $\mathrm{Cu}$ as a function of pore size to determine whether mechanistic changes result from nano-scale confinement. The current reaction condition, $\mathrm{pH}=6$, is above the point of zero charge, $\mathrm{p}_{\mathrm{z}} \mathrm{c}$, of SBA-15 silica $\left(\mathrm{p}_{\mathrm{z}} \mathrm{c}=4.2\right)$ [47]. As a result, the silica surface is expected to be negatively charged, and the electrostatic interactions could be driving forces leading to the adsorption of free $\mathrm{Cu}^{2+}$ cations onto the silica surface. Building off the X-ray absorption data analysis by Cheah et al., $\mathrm{Cu}$ forms inner-sphere surface complexes with amorphous silica $[19,20]$. Additional analyses observed short $\mathrm{Cu}-\mathrm{Cu}$ distances (2.58-2.59 $\AA$ ), suggesting the formation of dimeric species adsorbed onto the amorphous silica surface. The bonding mode was concluded to be 
mono-dentate, demonstrated from the presence of only one unique $\mathrm{Cu}-\mathrm{Si}$ distance $(\sim 3.0 \AA)$, whereas a bidentate-bridging bonding mode would have resulted in two unique $\mathrm{Cu}-\mathrm{Si}$ distances, distinguishable spectroscopically $[19,20]$. However, with decreasing pore size, to a pore regime where nano-scale confinement effects may become apparent, it is unclear if the adsorption mode and $\mathrm{Cu}$ adsorption complex geometry would remain constant. Ferreira et al. demonstrated that $\mathrm{Cu}$ contains two electron orbitals of similar energy, therefore is subject to Jahn-Teller distortion in its octahedral coordination environment-creating a weak point in the hydration shell $[15,17]$. As a consequence, $\mathrm{Cu}$ was shown to change its coordination environment from outer-sphere to inner-sphere when adsorbed in narrow pores of mordenite (limiting pore diameter $0.26 \mathrm{~nm}$ ) [15, 17]. As shown by the significantly enhanced surface area normalized adsorption of $\mathrm{Cu}$ on SBA-15-4 over SBA-15-6 and SBA-15-8, our data may suggest changes in the adsorption complex geometry due to changes in water properties and steric strain of pore confinement. Our data agrees with previous studies showing that the changes in water properties and subsequent tendency for cations to form inner-sphere complexes preferentially enrich trace elements in nanopores $[48,49]$. Wang et al. demonstrated a nearly 10 -fold increase in the surface area normalized adsorption of both zinc $\left(\mathrm{Zn}^{2+}\right)$ and arsenate $\left(\mathrm{AsO}_{4}{ }^{3-}\right)$ on nano-porous alumina compared to alumina particles. Wang et al. attributed the observed increase in adsorption to the increase in the surface charge density inside nano-pores, and the impact of a larger proportion of structured water on ion hydration $[2,48,50]$. Furthermore, another study of uranium $\mathrm{U}^{6+}$ adsorption and desorption on mesoporous silica (MCM-41), demonstrated the formation of polymeric species-and eventual precipitation-inside the pores [51]. It is possible that the surface area normalized adsorption of $\mathrm{Cu}$ is enhanced in small mesopores $(4 \mathrm{~nm})$ due to $\mathrm{Cu}$ losing it hydration shell thus increasing its reactivity towards dimerization and surface adsorption.

\section{Effect of nano-scale confinement on adsorption kinetics}

The surface area-normalized time dependent $\mathrm{Cu}$ adsorption on SBA-15-8, SBA-15-6, and SBA-15-4 fit with pseudo-first-order kinetic model is shown in Fig. 4. The adsorption rate constants were obtained from the slope of the linear regression fit to the integrated rate equation. The experimentally determined rate constants show that the adsorption of $\mathrm{Cu}$ on SBA-15-4 is fastest, as is summarized in Fig. 5. The rate constants representing the adsorption kinetics of $\mathrm{Cu}$ on mesoporous silica are $0.048 \pm 0.003$, $0.059 \pm 0.003$, and $0.071 \pm 0.003 \mu \mathrm{mol} / \mathrm{m}^{2} \mathrm{~min}$ for SBA-158 , SBA-15-6, and SBA-15-4, respectively.
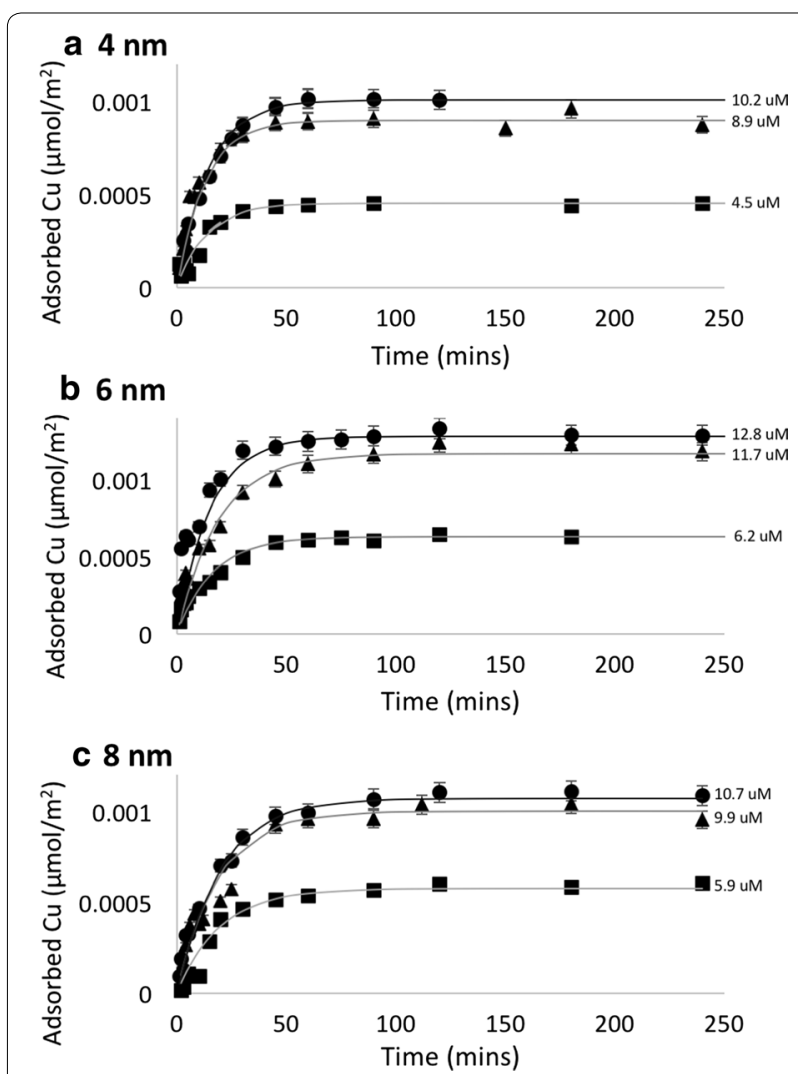

Fig. 4 Surface area normalize adsorption of Cu versus time in minutes for a SBA-15-4, b SBA-15-6, and c SBA-15-8. The final equilibrium concentrations are shown for each line

As seen in Fig. 5, the pseudo-first-order kinetic rates are inversely proportional to pore diameter; as the pore diameter decreases, the kinetic rate increases. Previous studies have summarized the dependence of surface tension [9], density [9], and dielectric constant [8] of water. Those parameters were approximated from the publications and added to Fig. 5 to compare to our data. As seen from Fig. 5, the changes in density, surface tension, and dielectric constant of water have a negative correlation with the adsorption kinetics quantified in our study. From these trends, we have concluded that the rate of $\mathrm{Cu}$ adsorption could be related to the decrease in the surface tension, density, and dielectric constant of water. These changes in water properties could increase the propensity of $\mathrm{Cu}$ to lose its hydration sphere and from inner-sphere complexes with the surface. We believe it is reasonable that these changes in the water properties will impact the rate of adsorption of $\mathrm{Cu}$; as the pore decreases in size, a decrease in surface tension and density would allow more rapid flow inside the pores; a decrease in the dielectric constant would lead to a decrease in the hydration energy of the $\mathrm{Cu}$ atom, thus allowing for more rapid adsorption on the surface. 


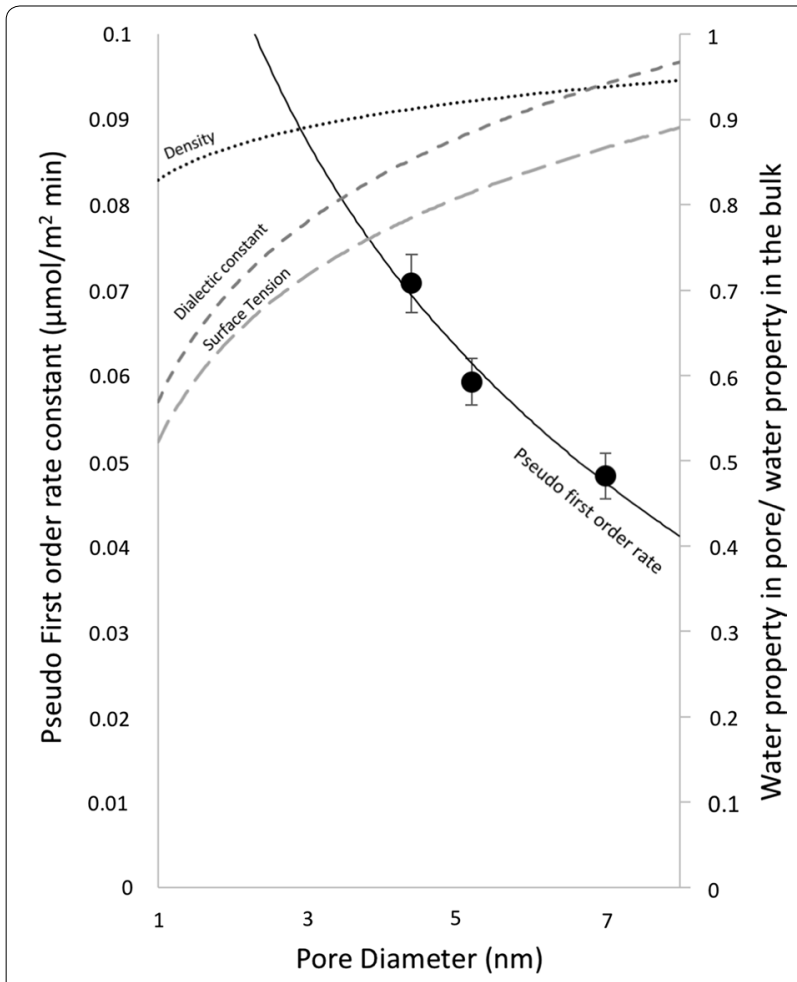

Fig. 5 Pseudo-first-order rate constant for $\mathrm{Cu}$ adsorption on mesoporous silica ( $\mu \mathrm{mol} / \mathrm{m}^{2} \mathrm{~min}$ ) as a function of pore size. Approximated water properties as function of pore size were obtained from previous studies for dielectric constant [8], surface tension [9], and density [9]

\section{Intraparticle diffusion}

Further data interpretation of the $\mathrm{Cu}$ adsorption kinetics was evaluated using the Weber and Morris intraparticle diffusion model [31, 33, 52, 53]. This model provides additional information regarding the modes of adsorption and breaks down the adsorption rate into external mass transfer and intraparticle diffusion steps [34]. The intraparticle model suggests that adsorption occurs via three steps:

1. External mass transfer of adsorbate from the bulk solution to the adsorbent surface;

2. Adsorbate diffusion from external surface into the adsorbent pores;

3. Adsorption of adsorbate at the surface reactive sites.

Step three is assumed to be rapid in comparison to the two diffusion steps; therefore, the overall rate is a combination of external mass transfer and intraparticle diffusion [31, 52]. The intraparticle diffusion plots were generated by plotting $\mathrm{q}_{\mathrm{t}}$ versus $\mathrm{t}^{0.5}$, as described in Eq. 13 .

$$
q_{t}=k_{i} t^{0.5}
$$

where $k_{i}$ is the diffusion rate constant $\frac{\mu m o l}{m^{2} * \min ^{0.5}}$. The resulting plots from this model are best represented with a multi-linear regression. The multi-linearity represents the rate dependency on film diffusion early in the reaction, and the eventual rate dependence on intraparticle diffusion in later time regimes [21, 52]. For our analysis, we utilized the Piecewise Linear Regression (PLR) Excel Spreadsheet made available to us [52]. This spreadsheet performs a statistical analysis based upon F-ratio and evidence testing to determine the best fit of the intraparticle diffusion plot [52].

The intraparticle diffusion plots are shown in Fig. 6. Each intraparticle diffusion plot was fit using the PLR spreadsheet and fit with linear segments and breakpoints of those functions that best represented the system. As a general trend, our data shows adsorption begins with a period of rapid film diffusion, followed by subsequent slower adsorption step representing intraparticle diffusion, until equilibrium is reached. Each kinetic profile was fit with two linear segments and the slopes of the film diffusion section was fit to the plots in Fig. 6. The breakpoints were calculated to be $50 \pm 2,49 \pm 1$, and $32 \pm 8 \mathrm{~min}$ for SBA-15-8, SBA-15-6, and SBA-154 , respectively. These breakpoints were calculated as an average from various initial concentrations of $\mathrm{Cu}$. From the breakpoints, the time regimes dependent on external mass transfer or intraparticle diffusion were established and fit with linear regression lines.

The slopes of linear segments, $\mathrm{k}_{\mathrm{i}}$, describing the external mass transfer for SBA-15-8, SBA-15-6, and SBA-15-4 represent the diffusion rate constant. The $k_{i}$ values versus the $\mathrm{q}_{\max }$ is shown in Fig. 7. As the $\mathrm{q}_{\max }$ increases, the $\mathrm{k}_{\mathrm{i}}$ value increases. This suggests that with higher $\left[\mathrm{Cu}^{2+}\right]$ in the system, the external mass transfer from the bulk to the silica film is more rapid. This observed trend is true for all three SBA-15 substrates. Additionally, the curves in Fig. 7 for SBA-15-8 and SBA-15-6 are nearly identical, however the curve representing the relationship between $\mathrm{k}_{\mathrm{i}}$ and $\mathrm{q}_{\mathrm{eq}}$ for SBA-15-4 is different. From this plot, it can be concluded that the film diffusion rate for $\mathrm{Cu}$ adsorption on SBA-15-4 is more rapid than on the larger pores. Once again, this can be attributed to the net effects of changes to the water properties (i.e. dielectric constant, density, and surface tension) and subsequent interaction of water with $\mathrm{Cu}$ and water with the silica surface.

\section{Conclusions and future work}

This experimental study presents a systematic approach to quantify the effects of nano-scale confinement on metal adsorption. While nano-scale confinement effects have been observed in mesoporous systems, this is the 


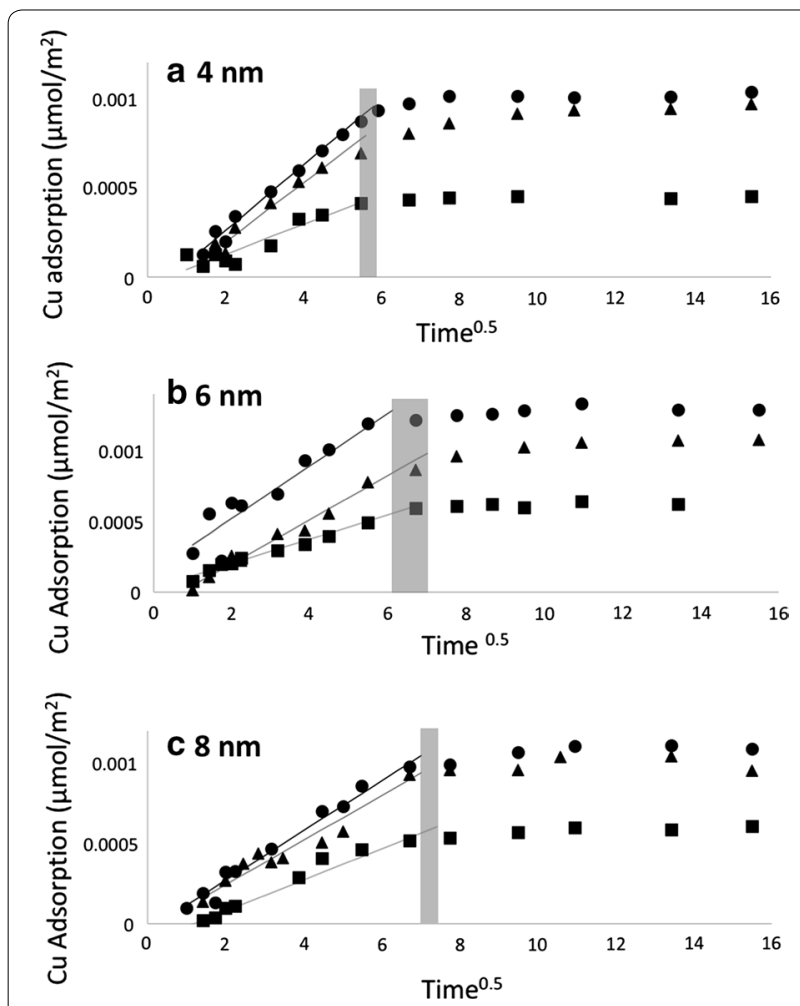

Fig. 6 Intraparticle diffusion plots for the adsorption of $\mathrm{Cu}$ with on a SBA-15-4, b SBA-15-6, and c SBA-15-8. The section of the intraparticle diffusion model representing the external mass transfer was fit with a linear regression line based upon Piecewise Linear Regression [52]. The shaded regions represent the time break points used for the slope analysis

first, to our knowledge, study quantifying nano-scale confinement effects on the adsorption of $\mathrm{Cu}$ on mesoporous silica. Through an analysis of the surface area normalized adsorption isotherms and adsorption kinetics of $\mathrm{Cu}$ on SBA-15-8, SBA-15-6, ad SBA-15-4, we concluded that nano-scale confinement enhances both the adsorption maximum, and $\mathrm{Cu}$ adsorption reaction rate. Evidence of this is shown in the significant increase in the surface area normalized adsorption maximum of $\mathrm{Cu}$ on SBA15-4 compared to both SBA-15-6 and SBA-15-8 across all isotherm models. Further, the pseudo-first-order reaction rate constant increased with decreasing pore size. The intraparticle diffusion model was applied, and it illustrates that external mass transfer diffusion constant increases with decreasing pore size, and we postulate that this rapid film diffusion in $4 \mathrm{~nm}$ pores was responsible for the observed increase in reaction rate. Future work should address molecular-scale speciation of $\mathrm{Cu}$ associated with mesoporous silica surfaces, using spectroscopic approaches.

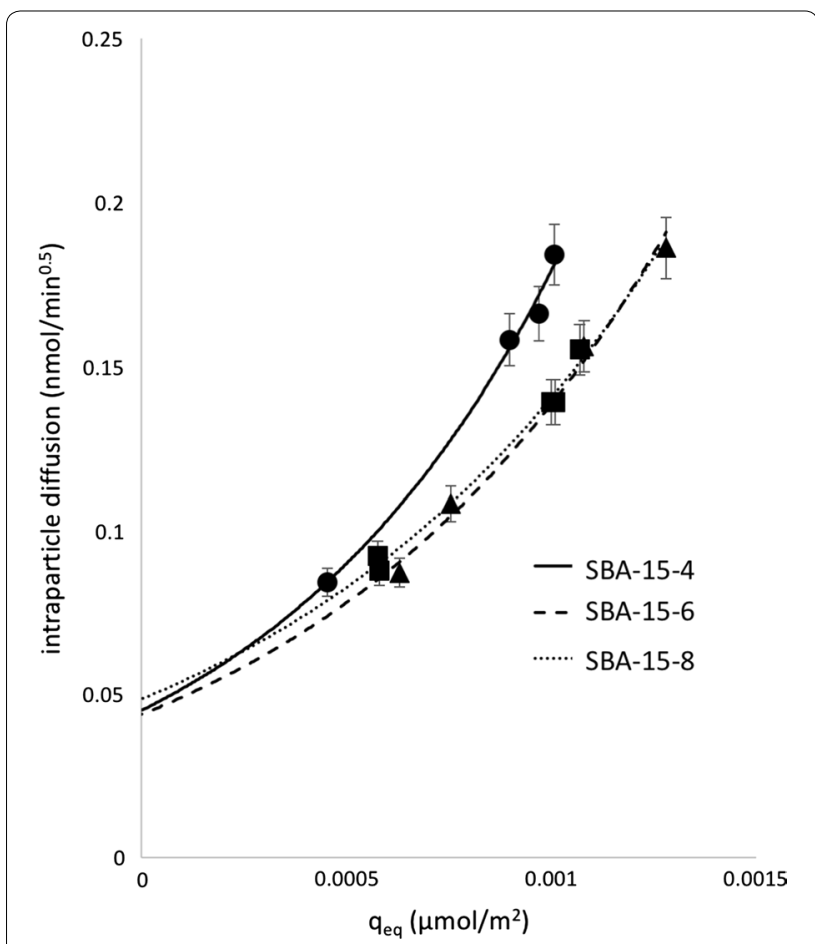

Fig. 7 Intraparticle diffusion constant, $k_{i}$, versus equilibrium adsorption of $\mathrm{Cu}$, $\mathrm{q}_{\mathrm{eq}}$, on SBA-15-4, SBA-15-6, and SBA-15-8

We believe this study will aid in the understanding of the impacts of cation adsorption in geologically relevant mesopores. This will increase our ability to anticipate cation fate and transport in shales and tight rocks. Further studies are needed to assess the metal coordination environment as a function of pore size, and correlate any changes in coordination number or bond angles or distances to the observed changes in macroscopic adsorption behavior.

\section{Additional file}

Additional file 1: Figure S1. A copper speciation diagram as a function of solution $\mathrm{pH}$. Figure $\mathbf{S 2}$. The NLDFT pore size distribution plots of SBA15-8, SBA-15-6, and SBA-15-4. Figure S3. A plot showing the Langmuir equilibrium parameter, $R_{L^{\prime}}$, versus the initial copper concentration.

\section{Authors' contributions}

AGl led project development, AGI and AWK designed experimental program and analyzed data. ABT assisted with data collection. All authors, contributed to writing the manuscript. All authors read and approved the final manuscript.

\section{Acknowledgements}

The authors would like to thank Eric Coker for collecting BET on mesoporous silica samples. This work was supported by the US Department of Energy, Office of Science, Office of Basic Energy Sciences, Chemical Sciences, Geosciences and Biosciences Division. Sandia National Laboratories is a multimission laboratory managed and operated by National Technology and 
Engineering Solutions of Sandia, LLC., a wholly owned subsidiary of Honeywell International, Inc., for the U.S. Department of Energy's National Nuclear Security Administration under contract DE-NA-0003525.

\section{Competing interests}

The authors declare that they have no competing interests.

\section{Publisher's Note}

Springer Nature remains neutral with regard to jurisdictional claims in published maps and institutional affiliations.

Received: 26 February 2018 Accepted: 8 June 2018

Published online: 26 June 2018

\section{References}

1. Weber WJ, Huang WL (1996) A distributed reactivity model for sorption by soils and sediments. 4. Intraparticle heterogeneity and phase-distribution relationships under nonequilibrium conditions-response. Environ Sci Technol 30(10):3130-3131

2. Wang YF et al (2003) Surface chemistry of mesoporous materials: effect of nanopore confinement. Struct Prop Relationsh Oxide Surf Interfaces II 751:121-125

3. Ilgen AG et al (2017) Shales at all scales: exploring coupled processes in mudrocks. Earth Sci Rev 166:132-152

4. Sing KSW et al (1985) Reporting physisorption data for gas solid systems with special reference to the determination of surface-area and porosity (Recommendations 1984). Pure Appl Chem 57(4):603-619

5. Logar NZ, Kaucic V (2006) Nanoporous materials: from catalysis and hydrogen storage to wastewater treatment. Acta Chim Slov 53(2):117-135

6. Levinger NE (2002) Water in confinement. Science 298(5599):1722-1723

7. Marti J et al (2006) Molecular dynamics simulation of liquid water confined inside graphite channels: dielectric and dynamical properties. J Phys Chem B 110(47):23987-23994

8. Senapati S, Chandra A (2001) Dielectric constant of water confined in a nanocavity. J Phys Chem B 105(22):5106-5109

9. Takei T et al (2000) Changes in density and surface tension of water in silica pores. Colloid Polym Sci 278(5):475-480

10. Nelson JM et al (2014) Probing the mechanisms of pore size dependent geochemistry: effects of meso-confinement on Zn sorption in mesoporous silica. In: abstracts of papers of the American chemical society, vol 247

11. Zimmerman AR et al (2004) Protection of mesopore-adsorbed organic matter from enzymatic degradation. Environ Sci Technol 38(17):4542-4548

12. Kim YH et al (2004) Arsenic removal using mesoporous alumina prepared via a templating method. Environ Sci Technol 38(3):924-931

13. Madden AS, Hochella MF, Luxton TP (2006) Insights for size-dependent reactivity of hematite nanomineral surfaces through $\mathrm{Cu}^{2+}$ sorption. Geochim Cosmochim Acta 70(16):4095-4104

14. Zeng $\mathrm{H}$ et al (2009) Nanoscale size effects on uranium(VI) adsorption to hematite. Environ Sci Technol 43(5):1373-1378

15. Ferreira DR et al (2012) An electron paramagnetic resonance spectroscopy investigation of the retention mechanisms of $\mathrm{Mn}$ and $\mathrm{Cu}$ in the nanopore channels of three zeolite minerals. Clays Clay Miner 60(6):588-598

16. Ferreira DR, Schulthess CP, Giotto MV (2012) An investigation of strong sodium retention mechanisms in nanopore environments using nuclear magnetic resonance spectroscopy. Environ Sci Technol 46(1):300-306

17. Ferreira DR, Schulthess CP, Kabengi NJ (2012) Calorimetric evidence in support of the nanopore inner sphere enhancement theory on cation adsorption. Soil Chem 77:94-99

18. Moore JW (1991) Copper, in inorganic contaminants of surface water: research and monitoring priorities. Springer, New York

19. Cheah SF, Brown GE, Parks GA (1998) XAFS spectroscopy study of Cu(II) sorption on amorphous $\mathrm{SiO}_{2}$ and gamma- $\mathrm{Al}_{2} \mathrm{O}_{3}$ : effect of substrate and time on sorption complexes. J Colloid Interface Sci 208(1):110-128
20. Cheah SF, Brown GE, Parks GA (2000) XAFS study of Cu model compounds and $\mathrm{Cu}^{2+}$ sorption products on amorphous $\mathrm{SiO}_{2}$, gamma$\mathrm{Al}_{2} \mathrm{O}_{3}$, and anatase. Am Miner 85(1):118-132

21. Rengaraj $S$ et al (2004) Removal of copper from aqueous solution by aminated and protonated mesoporous aluminas: kinetics and equilibrium. J Colloid Interface Sci 273(1):14-21

22. Chiron N, Guilet R, Deydier E (2003) Adsorption of $\mathrm{Cu}(\mathrm{II})$ and Pb(II) onto a grafted silica: isotherms and kinetic models. Water Res 37(13):3079-3086

23. Aguado J et al (2009) Aqueous heavy metals removal by adsorption on amine-functionalized mesoporous silica. J Hazard Mater 163(1):213-221

24. Pinkas J (2005) Chemistry of silicates and alumino silicates. Ceram-Silik 49(4):287-298

25. Ojeda ML et al (2003) On comparing BJH and NLDFT pore-size distributions determined from N(2) sorption on SBA-15 substrata. Phys Chem Chem Phys 5(9):1859-1866

26. Ravikovitch PI, Neimark AV (2001) Characterization of micro- and mesoporosity in SBA-15 materials from adsorption data by the NLDFT method. J Phys Chem B 105(29):6817-6823

27. Carrott MMLR et al (2001) Adsorption of nitrogen, neopentane, $n$-hexane, benzene and methanol for the evaluation of pore sizes in silica grades of MCM-41. Microporous Mesoporous Mater 47(2-3):323-337

28. Ndungu K (2012) Model predictions of copper speciation in coastal water compared to measurements by analytical voltammetry. Environ Sci Technol 46(14):7644-7652

29. Langmuir I (1918) The adsorption of gases on plane surfaces of glass, mica and platinum. J Am Chem Soc 40:1361-1403

30. Elkady MF, El-Aassar MR, Hassan HS (2016) Adsorption profile of basic dye onto novel fabricated carboxylated functionalized co-polymer nanofibers. Polymers 8(5):177

31. Nethaji S, Sivasamy A, Mandal AB (2013) Adsorption isotherms, kinetics and mechanism for the adsorption of cationic and anionic dyes onto carbonaceous particles prepared from Juglans regia shell biomass. Int J Environ Sci Technol 10(2):231-242

32. Smith KS (1999) Metal sorption on mineral surfaces: an overview with examples relating to mineral deposits. In: Plumblee GS, Logsdon MJ (eds) The environmental geochemistry of mineral deposits. Society of Economic Geologists, Inc, Littleton, pp 161-182

33. Mahmoud MA (2015) Kinetics and thermodynamics of aluminum oxide nanopowder as adsorbent for Fe(III) from aqueous solution. Beni-Suef Univ J Basic Appl Sci 4(2):142-149

34. Vadivelan V, Kumar KV (2005) Equilibrium, kinetics, mechanism, and process design for the sorption of methylene blue onto rice husk. J Colloid Interface Sci 286(1):90-100

35. Freundlich $\mathrm{H}$ (1906) Concerning adsorption in solutions. Zeitschrift Fur Physikalische Chemie-Stochiometrie Und Verwandtschaftslehre 57(4):385-470

36. Everett JA (ed) (1998) Adsorption models in adsorption of metals by geomedia. Academic Press, San Diego

37. Dabrowski A (2001) Adsorption - from theory to practice. Adv Colloid Interface Sci 93(1-3):135-224

38. Polanyi M (1963) Potential theory of adsorption. Science 141(358):1010

39. Corbett JF (1972) Pseudo first-order kinetics. J Chem Educ 49(10):663

40. Creed J, Brockhoff C, Martin T (1994) EPA method 200.8, revision 5.4. Determination of trace elements in waters and wastes by inductively coupled plasma - mass spectrometry. U.E.P. Agency, Knoxville

41. Pollock RA et al (2011) Size and spatial distribution of micropores in SBA-15 using CM-SANS. Chem Mater 23(17):3828-3840

42. Galarneau A et al (2001) True microporosity and surface area of mesoporous SBA-15 silicas as a function of synthesis temperature. Langmuir 17(26):8328-8335

43. Kruk M et al (2000) Characterization of the porous structure of SBA-15. Chem Mater 12(7):1961-1968

44. Zhuravlev LT (2000) The surface chemistry of amorphous silica. Zhuravlev model. Colloids Surf A Physicochem Eng Aspects 173(1-3):1-38

45. Ide M et al (2013) Quantification of silanol sites for the most common mesoporous ordered silicas and organosilicas: total versus accessible silanols. Phys Chem Chem Phys 15(2):642-650 
46. Giret S, Hu Y, Masoumifard N, Boulanger J, Juere E, Kleitz F, Lariviere D (2018) Selective separation and preconcentration of scadium with mesoporous silica. Appl Mater Interfaces 10:448-457

47. Kosmulski M (2009) pH-dependent surface charging and points of zero charge. IV. Update and new approach. J Colloid Interface Sci 337(2):439-448

48. Wang YF et al (2003) Nanogeochemistry: geochemical reactions and mass transfers in nanopores. Geology 31(5):387-390

49. Kalluri RK, Konatham D, Striolo A (2011) Aqueous $\mathrm{NaCl}$ solutions within charged carbon-slit pores: partition coefficients and density distributions from molecular dynamics simulations. J Phys Chem C 115(28):13786-13795
50. Wang YF (2014) Nanogeochemistry: nanostructures, emergent properties and their control on geochemical reactions and mass transfers. Chem Geol 378:1-23

51. Singer DM, Guo H, Davis JA (2014) U(VI) and Sr(II) batch sorption and diffusion kinetics into mesoporous silica (MCM-41). Chem Geol 390:152-163

52. Malash GF, El-Khaiary MI (2010) Piecewise linear regression: a statistical method for the analysis of experimental adsorption data by the intraparticle-diffusion models. Chem Eng J 163(3):256-263

53. Wei W et al (2016) Biosorption of $\mathrm{Pb}(\mathrm{II})$ from aqueous solution by extracellular polymeric substances extracted from Klebsiella sp. J1: adsorption behavior and mechanism assessment. Sci Rep 6:31575

\section{Submit your manuscript to a SpringerOpen ${ }^{\circ}$ journal and benefit from:}

- Convenient online submission

- Rigorous peer review

- Open access: articles freely available online

- High visibility within the field

- Retaining the copyright to your article

Submit your next manuscript at $\boldsymbol{\nabla}$ springeropen.com 